\title{
Influence of Textural Properties and Surface Fractal Dimensions on the Cobalt Adsorption Behavior of Rice Hull Ash Prepared via Solid Combustion
}

\author{
Norma A. Sánchez-Flores, ${ }^{a}$ Francisco Granados-Correa ${ }^{*, b}$ and Silvia Bulbulian ${ }^{a}$ \\ ${ }^{a}$ Centro de Ciencias Aplicadas y Desarrollo Tecnológico, Universidad Nacional Autónoma de \\ México, Circuito Exterior S/N, Ciudad Universitaria, A.P. 70-186, C.P. 04510, México D. F., México \\ ${ }^{b}$ Departamento de Química, Instituto Nacional de Investigaciones Nucleares, A.P. 18-1027, \\ Col. Escandón, Delegación Miguel Hidalgo, C.P. 1180, México D.F., México
}

\begin{abstract}
Rice hull ash was prepared via a fast chemical combustion method with ammonium nitrate, urea and milled rice hull. Urea was used as the chemical fuel. The mixture was heated to various temperatures $\left(100\right.$ to $\left.1000{ }^{\circ} \mathrm{C}\right)$, and the resulting products were compared with products obtained via calcination, in which samples were heated to the same temperatures for 2 hours. Changes in the structure, morphology, texture and surface fractal dimensions with respect to temperature were examined and found to be highly relevant for adsorption applications. The prepared powders were characterized physicochemically by X-ray diffraction and $\mathrm{N}_{2}$-physisorption measurements. The surface fractal dimensions of the prepared materials were calculated from $\mathrm{N}_{2}$-adsorptiondesorption isotherms. The results indicate that the fast combustion samples have larger surface fractal dimensions than calcined samples. A correlation between fractal dimensions and $\mathrm{Co}^{2+}$ ion adsorption was found. The present study demonstrates the importance of textural properties and surface fractal dimensions in the adsorption performance of adsorbents.
\end{abstract}

Keywords: rice hull ash (RHA), cobalt adsorption capacity, combustion process, calcination treatment, surface fractal dimensions

\section{Introduction}

Rice hull (RH) is a low-cost agricultural waste obtained from rice hull mills. RH is used by various industries as a boiler fuel to produce steam. Burning rice hull for long periods generate energy results in the waste product rice hull ash (RHA), which is rich in silica and has a considerable cation exchange capacity due to the polar groups present on its surface. Srivastava et al. ${ }^{1}$ and An et al. ${ }^{2}$ reported that RHA is an effective adsorbent of metal ions from water. It is well known that the efficiency and cost-effectiveness during a waste water adsorption process is determined by choosing suitable potential adsorbent particles with improved structural and textural characteristics. ${ }^{3}$ In the search for materials with appropriate physico-chemical characteristics to be used as efficient and low cost adsorbents many efforts, including the development of chemical processes, have been developed to reduce the hazardous effects of toxic pollutants. ${ }^{4,5}$ On the other hand, combustion synthesis is a rapid chemical process based on the explosive

*e-mail: francisco.granados@inin.gob.mx decomposition of urea or other organic fuels. ${ }^{6}$ This decomposition provides heat for calcinations and produces high temperatures. ${ }^{7}$ Combustion synthesis has been used to prepare a variety of advanced ceramics, composites, alloys, and nanomaterials. ${ }^{8}$ Chemical combustion provides an attractive alternative to other complex synthesis methods, requiring minimal use of specialized equipment and allowing for rapid preparation while producing a product with optimal structural and functional properties. It has been shown that the combustion process favors the retention of metallic chemical species on adsorbent solids due to their improved textural characteristics. ${ }^{9,10}$ Materials prepared by chemical combustion have attracted increasing interest because of their novel properties and potential technological applications (e.g., adsorption, adhesion, surface diffusion, and catalysis). The adsorption process with chemical combustion prepared materials has significant advantages over chemical precipitation, coagulation, chemical oxidation and reduction, ion exchange, reverse osmosis, membrane processes, filtration and other separation technologies reported in the specialized literature, ${ }^{11-13}$ due to lower operation cost, high selectivity, high efficiency 
in removing very low levels of heavy metals from dilute solutions and easy handling.

Rice hull ash changes in the structure, morphology, texture and surface fractal dimensions with respect to temperature were examined and found to be highly relevant for adsorption applications.

The present study was performed to analyze the mesoporous characteristics and surface fractal dimensions of rice hull ash prepared via the fast chemical combustion method and the resulting products were compared with products obtained via the calcinations process in which samples were heated to the same temperatures for 2 hours. The effect of these characteristics on $\mathrm{Co}^{2+}$ ion adsorption from aqueous solutions was determined. The surface fractal dimension $\left(\mathrm{D}_{\mathrm{f}}\right)$ of a solid describes the solid's surface irregularities and heterogeneity associated with its physicochemical properties. The surface fractal dimension of a solid can determine the potential applications for that solid. A simple and fast fractal analysis using $\mathrm{N}_{2}$ gas adsorption is widely used to determine the degree of surface roughness within a solid. The degree of roughness can vary between two and three. ${ }^{14,15}$ It is worth noting that extensive studies of diverse materials have revealed surface fractality through fractal analysis. ${ }^{16-20}$ Such observations motivated us to apply fractal considerations to analyze adsorbent surface irregularities. These irregularities are indicative of surface active sites that are able to remove pollutants from water. As texture is the main difference between conventional and combustion-prepared materials, the adsorption properties of conventional and combustion-prepared materials may differ. ${ }^{18}$ Early research has measured the cobalt adsorption capacity of several materials; however, RHA has not been investigated to date. ${ }^{21-24}$

On the other hand, cobalt is a heavy metal that may cause both beneficial and harmful effects on human health when accumulated in living tissues. Cobalt is beneficial for humans because it is a component of vitamin B12, which is essential to maintain human health, and because it has been used as a treatment for anemia. However, at high concentrations, cobalt can have toxic effects on the lungs, including asthma, pneumonia, and wheezing. ${ }^{25}$ When cobalt is regularly ingested through water, it causes damage mainly in the digestive tract due to its corrosiveness, but the major cobalt toxic factors are its carcinogenic and teratogenic properties. ${ }^{26}$ Therefore, cobalt removal from waste water is of primary concern.

In this paper, the $\mathrm{Co}^{2+}$ retention values of rice hulls subjected to a chemical combustion process are compared to those of rice hulls subjected to a calcination process, and the textural morphologies, fractal surface dimensions, and structural properties of these materials are determined to explain differences observed in the retention values.

\section{Experimental}

\section{Materials and reagents}

In this study, rice hull ( $\mathrm{RH})$ from Zacatepec, Morelos, México, was used without any pretreatment except for sieving to remove fine particles. $\mathrm{NH}_{4} \mathrm{NO}_{3}$ (Sigma Aldrich ACS reagent 99-100 wt.\% purity), $\mathrm{NH}_{2} \mathrm{CONH}_{2}$ (Sigma Aldrich ACS reagent 99-100 wt.\% purity), and $\mathrm{Co}\left(\mathrm{NO}_{3}\right)_{2} \cdot 6 \mathrm{H}_{2} \mathrm{O}$ (Baker ACS reagent 100 wt.\% purity) were used as starting analytical grade chemical precursors without further purification. $\mathrm{NaOH}$ and $\mathrm{HCl}$ were purchased from S.D. fine chemicals. $\mathrm{Co}^{2+}$ ion solutions were prepared by dissolving $\mathrm{Co}\left(\mathrm{NO}_{3}\right)_{2} \cdot 6 \mathrm{H}_{2} \mathrm{O}$ in distilled water.

\section{Adsorbents and their characterization}

RH samples were modified by a solid-combustion process as follows: samples were first milled in an agate mortar, dried for $2 \mathrm{~h}$ at $100{ }^{\circ} \mathrm{C}$ in an oven and then $1.5 \mathrm{~g}$ of urea, $1.5 \mathrm{~g}$ of $\mathrm{NH}_{4} \mathrm{NO}_{3}$, and $3 \mathrm{~mL}$ of distilled water were homogeneously mixed. Next, the obtained solids were heated in a muffle furnace for $5 \mathrm{~min}$ at temperatures ranging from 100 to $1000{ }^{\circ} \mathrm{C}$. The resulting samples were labeled as COMB-100, COMB-200, COMB-300, COMB-400, COMB-500, СOMB-600, СOMB-700, COMB-800, COMB-900, and COMB-1000 according to the heating temperature.

Calcined samples in the presence of air were prepared by subjecting RH samples, milled and dried as described in the previous paragraph, to a solid-calcination method in a muffle furnace for $2 \mathrm{~h}$ at temperatures ranging from 100 to $1000{ }^{\circ} \mathrm{C}$. The samples were labeled as CAL-100, CAL-200, CAL-300, CAL-400, CAL-500, CAL-600, CAL-700, CAL-800, CAL-900, and CAL-1000 according to the heating temperature.

Physicochemical characterization of the samples was performed using standard procedures. X-ray powder diffraction (XRD) patterns of the RHA samples modified using the solid-combustion and solid-calcination methods were obtained using a diffractometer (Siemens D-5000) coupled to a copper anode X-ray tube. We selected the $\mathrm{K}_{\alpha 1}$ radiation $(\alpha=1.54186 \AA$ ) with a diffracted-beam monochromator. The diffraction patterns were scanned with $2 \theta$ angle sweeps of $5^{\circ}$ to $70^{\circ}$ and a scan step of $0.035^{\circ}$ per $7 \mathrm{~s}$. The resulting compounds were identified by comparison to files from the corresponding Joint Committee on Powder Diffraction Standards (JCPDS). The morphologies, 
sizes, and shapes of the modified solid-combustion and solid-calcination grain samples were determined using a JEOL-JMS 5900 LV scanning electron microscope (SEM). The Brunauer-Emmett-Teller (BET) specific surface areas, mean pore diameters, total pore volumes, and $\mathrm{N}_{2}$ adsorption/ desorption isotherms of the materials were determined by nitrogen-physisorption measurements using a BEL Japan INC model Belsorp Max equipment at $77 \mathrm{~K}$ with a multipoint technique. All samples were degassed at $200{ }^{\circ} \mathrm{C}$ for $2 \mathrm{~h}$ under vacuum prior to study. To determine the surface irregularities of as-prepared materials, the surface fractal dimensions of the materials were determined directly from physical single $\mathrm{N}_{2}$ adsorption/desorption isotherms at $77 \mathrm{~K}$ based on Pfeifer's theory ${ }^{27}$ and linear equation 1 :

$\ln \left(\mathrm{V} / \mathrm{V}_{\mathrm{m}}\right)=\left(\mathrm{D}_{\mathrm{f}}-3\right) / 3\left[\ln \left(\ln \left(\mathrm{p}_{\mathrm{o}} / \mathrm{p}\right)\right)\right]+\mathrm{constant}$

where $\mathrm{V}_{\mathrm{m}}$ is the molar volume, $\mathrm{V}$ is the $\mathrm{N}_{2}$ gas volume at standard pressure and temperature adsorbed at equilibrium pressure $\mathrm{p}$ and $\mathrm{p}_{\mathrm{o}}$ is the adsorbate saturation pressure. ${ }^{18}$ The fractal dimensions were determined experimentally from the slopes of the plot of $\ln \left(\mathrm{V} / \mathrm{V}_{\mathrm{m}}\right) v s \cdot \ln \left(\ln \left(\mathrm{p}_{\mathrm{o}} / \mathrm{p}\right)\right)$, taking the value of $\left(D_{f}-3\right) / 3$ from the linear portion of the plot. Solid surfaces can exhibit surface fractal dimensions in the range of $2 \leq D_{f}<3$, where $D_{f} \leq 2$ indicates a regular or perfectly smooth surface and $\mathrm{D}_{\mathrm{f}}=3$ indicates a highly rough or irregular surface. ${ }^{17}$

\section{Batch adsorption studies}

$\mathrm{Co}^{2+}$ adsorption studies using a batch technique at room temperature $\left(21^{\circ} \mathrm{C}\right)$ were performed. RHA samples $(100 \mathrm{mg})$ modified by the solid-combustion or solid-calcination methods were added to $10 \mathrm{~mL}$ of a $50 \mathrm{mg} \mathrm{L}^{-1}$ cobalt solution $\left(\mathrm{Co}\left(\mathrm{NO}_{3}\right)_{2} \cdot 6 \mathrm{H}_{2} \mathrm{O}\right)$ in water $(\mathrm{pH}=6.32)$, and the mixtures were stirred constantly for $2 \mathrm{~h}$ as a pre-established equilibrium time. ${ }^{28}$ Phases were then separated by centrifugation for $5 \mathrm{~min}$ at $6000 \mathrm{rpm}$. Then, a 1-mL aliquot of the liquid phase was analyzed by ultraviolet-visible spectroscopy (UV-Vis) using a PerkinElmer Spectrometer Lambda 10 at $\lambda=265 \mathrm{~nm}$. The $\mathrm{Co}^{2+}$ ion concentration was then determined using a previously calibrated curve. The peroxide and sodium bicarbonate methods were used to achieve green color complex development. ${ }^{29}$ All experimental data are averages of duplicate measurements. We obtained good reproducibility, with standard errors usually less than 5\% of the mean values. Equilibrium $\mathrm{pH}$ values at the ends of experiments were measured using a digital $\mathrm{pH}$-meter (Cole-Parmer model 05669-20) combined with a glass electrode. $\mathrm{pH}$ values measured were found to be between
5.2 and 7.6. The amount of $\mathrm{Co}^{2+}$ ions adsorbed by the modified samples was determined at various temperatures using the following equation:

$\mathrm{q}_{\mathrm{e}}=\left[\left(\mathrm{C}_{\mathrm{o}}-\mathrm{C}_{\mathrm{e}}\right) \mathrm{Vs}\right] / \mathrm{m}$

where $\mathrm{q}_{\mathrm{e}}$ is the retention per gram of rice hull ash at equilibrium $\left(\mathrm{mg} \mathrm{g}^{-1}\right)$, Vs is the volume of the solution (L), $\mathrm{m}$ is the weight of rice hull ash $(\mathrm{g})$, and $\mathrm{C}_{\mathrm{o}}$ and $\mathrm{C}_{\mathrm{e}}$ the initial and equilibrium cobalt concentrations $\left(\mathrm{mg} \mathrm{L}^{-1}\right)$, respectively.

\section{Results and Discussion}

All prepared samples were examined by X-ray diffraction to determine phase development. Figure 1 shows the X-ray diffraction patterns of samples modified by the solid-combustion technique. According to crystal structure analyses, temperatures between 400 and $800{ }^{\circ} \mathrm{C}$ resulted in non-crystallized solid-combustion samples. Amorphous silica was found in all of the samples. According to JCPDS file 00-039-1425, the well-defined peaks observed at $21.9,31.4$ and 36.1 degrees $2 \theta$ for the sample heated between 900 and $1000{ }^{\circ} \mathrm{C}$ correspond to the structure of cristobalite $\left(\mathrm{SiO}_{2}\right)$. The shoulder observed between 20.5 and 21.5 degrees $2 \theta$ for the samples corresponds to the structure of tridymite (JCPDS 00-042-1401). The maximum diffraction peaks observed at temperatures between 100 and $300{ }^{\circ} \mathrm{C}$ correspond to the decomposition products of the analytical reagents used during the combustion process. Traces of ammonium nitrate (JCPDS 01-085-0600), urea (JCPDS 00-001-0444), and silicon dioxide (JCPDS 00-045-0131) are observed at $100{ }^{\circ} \mathrm{C}$ and vanish as the temperature increases.

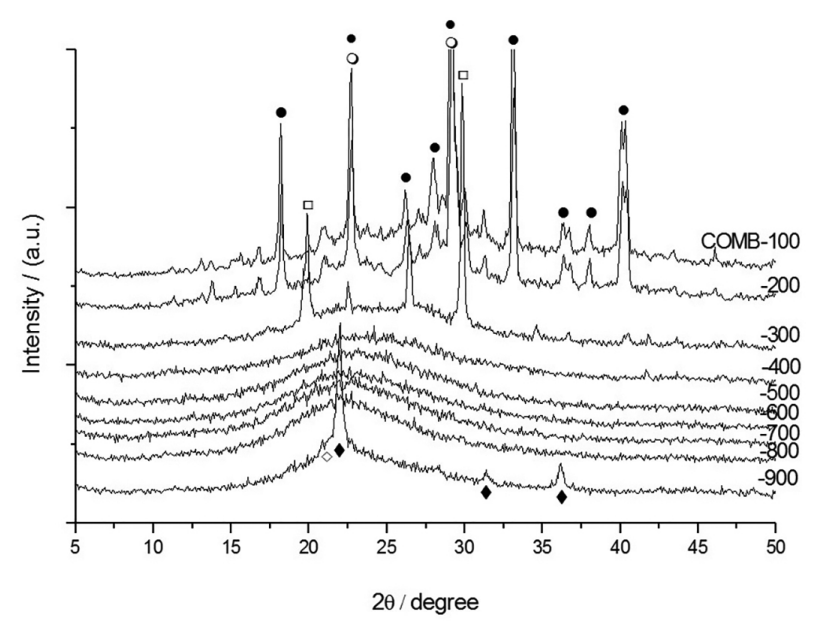

Figure 1. XRD patterns showing the crystalline development of solidcombustion rice-hull samples prepared at different temperatures for 5 minutes. Ammonium nitrate $(\bullet)$; silica $(\square)$; urea $(\bigcirc)$; cristobalite $(\bullet)$ and tridymite $(\diamond)$ are observed. 
Solids modified by the solid-calcination treatment also show well-defined diffraction peaks in the samples treated from 800 to $1000{ }^{\circ} \mathrm{C}$ (Figure 2). The results correspond with the cristobalite spectra and indicate traces of tridymite in these samples. Additionally, the broad halo near $2 \theta=22^{\circ}$ is characteristic of vitreous silica in the powders heated between 100 and $700{ }^{\circ} \mathrm{C}$.

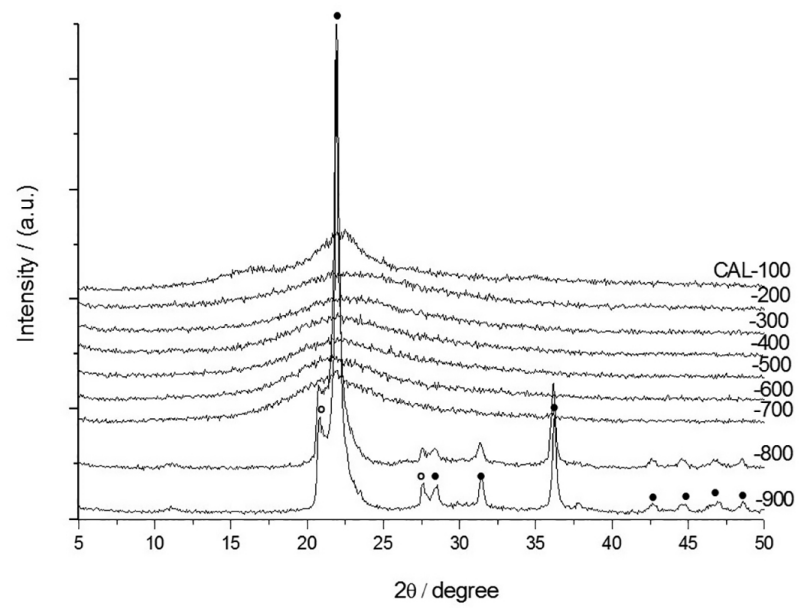

Figure 2. XRD patterns showing the crystalline development of solidcalcination rice-hull samples thermally treated at different temperatures for $2 \mathrm{~h}$. The presence of cristobalite $(O)$ and tridymite structure $(O)$ is clear at $900{ }^{\circ} \mathrm{C}$.

Micrographs obtained by SEM analysis (Figure 3) show the morphological evolution of the solid-combustion (Figure 3a), and solid-calcination (Figure 3b) RHA samples prepared in this work. The SEM images of the Figure 3a show that the surfaces of the solid-combustion are rough and small, feature typical of a material that is not well-crystallized. On the other hand, SEM images of Figure $3 b$, show that the particle surfaces of solid-calcination are smooth and big, feature of a well crystallized material.

Materials modified by the solid-combustion process reached high BET specific surface areas up to $243.06 \mathrm{~m}^{2} \mathrm{~g}^{-1}$, high total pore volumes, and small mean pore diameters (Table 1), suggesting that these fine powders might yield lower packing densities and might be more reactive than powders produced by conventional routes such as solidcalcination. As seen in Table 1, the increase in BET specific surface areas with increasing temperature (from 100 to $600{ }^{\circ} \mathrm{C}$ ) can be attributed to solid pore formation during the solid-combustion reaction, which involves the emission of gases such as $\mathrm{CO}_{2}, \mathrm{H}_{2} \mathrm{O}$, and $\mathrm{NO}_{2}$. Such gas emission may result directly from reactions between rice hulls, ammonium nitrate, and urea without the need for external oxygen. However, the BET specific surface areas were decreased as increased the temperature (from 700 to $1000{ }^{\circ} \mathrm{C}$ ), due to microcrystalline phase's formation that revealed the final

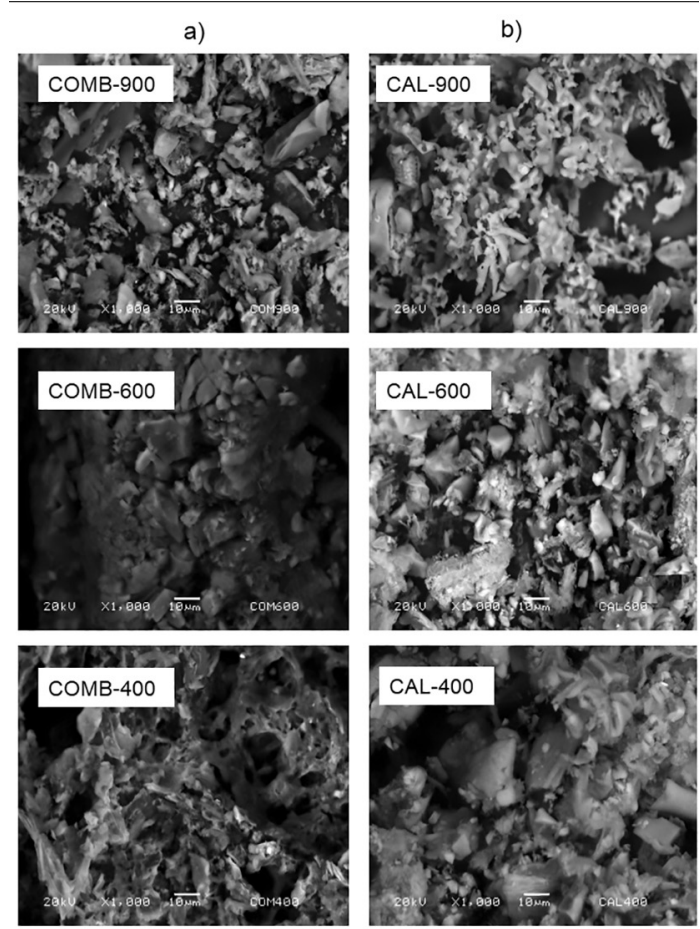

Figure 3. SEM image evolution at $1000 \times$ of rice hull ash samples prepared by (a) solid-combustion, thermally treated at different temperatures for 5 minutes; and (b) solid-calcination, thermally treated at different temperatures for $2 \mathrm{~h}$.

products after combustion temperature. On the other hand, BET specific surface areas of the solid-calcined samples increased as the temperature was increased from 100 and $300{ }^{\circ} \mathrm{C}$ reaching values of $160.8 \mathrm{~m}^{2} \mathrm{~g}^{-1}$ (Figure 4 ), due to the increase of RHA, however, from 300 to $1000^{\circ} \mathrm{C}$, decreased pattern of BET specific surface was observed reaching values of $0.32 \mathrm{~m}^{2} \mathrm{~g}^{-1}$ for $1000{ }^{\circ} \mathrm{C}$, due to a pore sintering resulted from the production of well-defined microcrystallized phases compounds, obtained at the increased calcination temperature, corroborating data by X-ray diffraction patterns results after calcinations. In addition, lower porous materials were observed on the external surfaces of the samples prepared via solid-calcination.

The solid-combustion process is advantageous because it generates powders with different particle morphologies and high BET specific surface areas. These properties determine the powder's $\mathrm{Co}^{2+}$ ion adsorption properties. As discussed above, the results show that BET specific surface area increases as a function of the heating temperature, with a maximum BET surface area of $243.06 \mathrm{~m}^{2} \mathrm{~g}^{-1}$ observed at $600{ }^{\circ} \mathrm{C}$ for $5 \mathrm{~min}$. BET surface area decreases to $82.48 \mathrm{~m}^{2} \mathrm{~g}^{-1}$ when the sample is thermally treated at $1000{ }^{\circ} \mathrm{C}$ for $5 \mathrm{~min}$. BET surface area trends are different for the solid-calcination process: the maximum BET surface area is obtained at $300{ }^{\circ} \mathrm{C}$. At higher temperatures, the porosity of the samples decreases. In both solid-combustion 
Table 1. Summary of $\mathrm{N}_{2}$ physisorption results of milling raw material and RHA samples prepared by solid-combustion and solid-calcination processes

\begin{tabular}{lcccccc}
\hline & \multicolumn{2}{c}{ BET specific surface area $/\left(\mathrm{m}^{2} \mathrm{~g}^{-1}\right)$} & \multicolumn{2}{c}{ Total pore volume $/\left(\mathrm{cm}^{3} \mathrm{~g}^{-1}\right)$} & \multicolumn{2}{c}{ Mean pore diameter $/ \mathrm{nm}$} \\
\hline Milling raw material & \multicolumn{2}{c}{1.29} & \multicolumn{2}{c}{0.0014} & & \multicolumn{2}{c}{31.46} \\
\hline $\begin{array}{l}\text { Temperature } \\
\text { treatment } /{ }^{\circ} \mathrm{C}\end{array}$ & Combustion & Calcination & Combustion & Calcination & Combustion & Calcination \\
\hline 100 & 1.54 & 1.56 & 0.0002 & 0.0126 & 16.166 & 32.435 \\
200 & 6.06 & 110.09 & 0.0192 & 0.1144 & 12.701 & 4.157 \\
300 & 14.51 & 160.84 & 0.0578 & 0.2561 & 15.954 & 6.360 \\
400 & 106.78 & 154.93 & 0.1304 & 0.2734 & 4.990 & 7.059 \\
500 & 215.94 & 86.25 & 0.1483 & 0.2319 & 2.746 & 10.753 \\
600 & 243.06 & 18.36 & 0.2082 & 0.1566 & 3.426 & 34.109 \\
700 & 225.55 & 7.98 & 0.1729 & 0.0919 & 3.068 & 46.070 \\
800 & 134.69 & 0.76 & 0.1362 & 0.0049 & 4.044 & 26.082 \\
900 & 163.86 & 0.74 & 0.1230 & 0.0011 & 3.003 & 6.317 \\
1000 & 82.48 & 0.32 & 0.0731 & 0.0008 & 3.562 & 10.741 \\
\hline
\end{tabular}

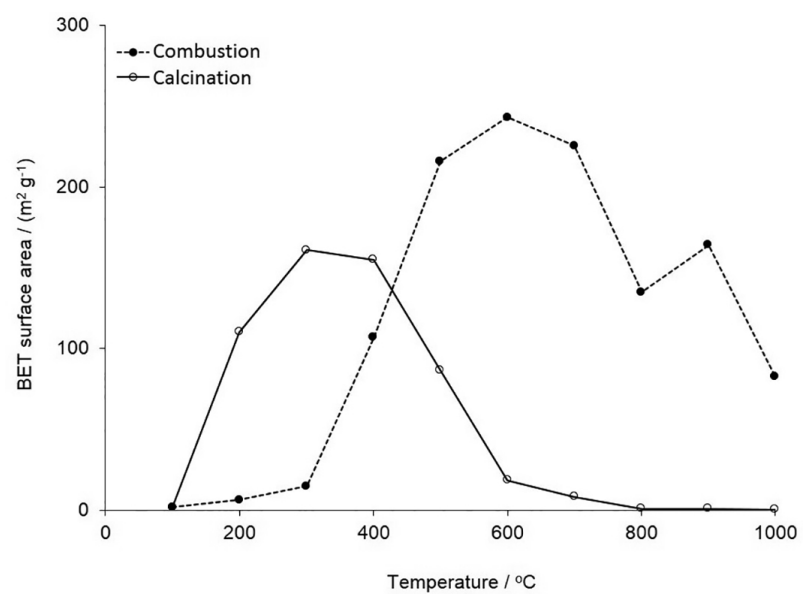

Figure 4. BET surface areas for samples treated at different temperatures.

and solid-calcination samples, BET specific surface area decreases when the temperature is increased from 700 to $1000{ }^{\circ} \mathrm{C}$ as was described above.

The nitrogen adsorption/desorption isotherms of all solid-combustion and solid-calcination samples prepared at various temperatures exhibited type IV behavior with hysteresis-loop isotherms (figure not shown). According to the International Union of Pure and Applied Chemistry (IUPAC), these isotherms correspond to mesoporous materials in which unrestricted monolayer-multilayer retention can occur. ${ }^{30}$ Such materials are potential candidates for cobalt adsorption.

Surface fractal dimension analyses for calcined samples returned valid ranges of $1.09<\left[\ln \left(\ln \left(\mathrm{p}_{\mathrm{o}} / \mathrm{p}\right)\right)\right]<-1.05$ with determination coefficients $\left(R^{2}\right)$ values from 0.6223 to 0.9977. $D_{f}$ values were found to be between 1 and 2, with $\mathrm{R}^{2}$ higher than 0.9 , implying a regular surface. Calcined samples up to $900{ }^{\circ} \mathrm{C}$ did not show fractality (Table 2).
In contrast, Figure 5 shows the fractal dimensions $\left(D_{f}\right)$ values of RHA samples prepared via a combustion method at different temperatures and their respective cobalt adsorption capacities $\left(\mathrm{q}_{\mathrm{e}}\right)$. All combustion samples have $\mathrm{D}_{\mathrm{f}}$ values between 1.436 and 2.656, and the surface geometry of combustion samples tends to become more rough when the combustion temperature is increased to $600{ }^{\circ} \mathrm{C}$ (Table 2). This observation may be attributed to the higher porosity of as-prepared combustion samples, suggesting that more porous surfaces are formed when temperature was increased up to $600{ }^{\circ} \mathrm{C}$, at higher temperatures the surface area and the fractal structure were decreased. Furthermore, fractal dimensions are directly correlated with the morphologies of the RHA combustion samples. The most plausible explanation for this particular trend is that bubbles in the combustion samples explode, forming craters and cavities on the surface. The frequency and intensity of such events vary considerably depending on the heat treatment temperature. ${ }^{18}$

The importance of the preparation method is evident by the textural and microstructural differences between combustion and calcination samples. Combustion prepared samples yield materials with higher porosities and higher cobalt adsorption capacities for treatment temperatures between 500 to $700{ }^{\circ} \mathrm{C}$ compared to calcined prepared samples with treatment temperatures between 200 to $400{ }^{\circ} \mathrm{C}$.

The best cobalt adsorption (85.98\%) was observed with the sample COMB-600 (equilibrium solution $\mathrm{pH}=7.4$ ). The equilibrium solution pHs ranged from 5.2 to 7.4 for the solid-combustion process and from 6.6 to 7.6 for the solid-calcination process. Only $\mathrm{Co}^{2+}$ chemical species are present in an aqueous solution; ${ }^{31}$ thus, cobalt adsorption 
Table 2. Fractal dimensions $\left(D_{f}\right)$ computed by single $N_{2}$ adsorption isotherms at $77 \mathrm{~K}$ and their determination coefficients $\left(R^{2}\right)$

\begin{tabular}{lccccc}
\hline Calcination sample & $\mathrm{D}_{\mathrm{f}}$ & $\mathrm{R}^{2}$ & Combustion sample & $\mathrm{D}_{\mathrm{f}}$ & $\mathrm{R}^{2}$ \\
\hline Cal-100 & 1.573 & 0.9408 & Comb-100 & 1.573 & 0.9408 \\
Cal-200 & 1.911 & 0.9969 & Comb-200 & 1.436 & 0.9784 \\
Cal-300 & 1.158 & 0.9944 & Comb-300 & 1.569 & 0.9936 \\
Cal-400 & 1.031 & 0.9919 & Comb-400 & 1.972 & 0.9877 \\
Cal-500 & 1.281 & 0.9836 & Comb-500 & 2.616 & 0.9867 \\
Cal-600 & 1.890 & 0.9977 & Comb-600 & 2.656 & 0.9936 \\
Cal-700 & 1.881 & 0.9893 & Comb-700 & 2.535 & 0.9948 \\
Cal-800 & 2.297 & 0.8048 & Comb-800 & 2.497 & 0.9979 \\
Cal-900 & 4.046 & 0.7807 & Comb-900 & 2.126 & 0.9854 \\
Cal-1000 & 4.323 & 0.6623 & Comb-1000 & 2.031 & 0.9809 \\
\hline
\end{tabular}

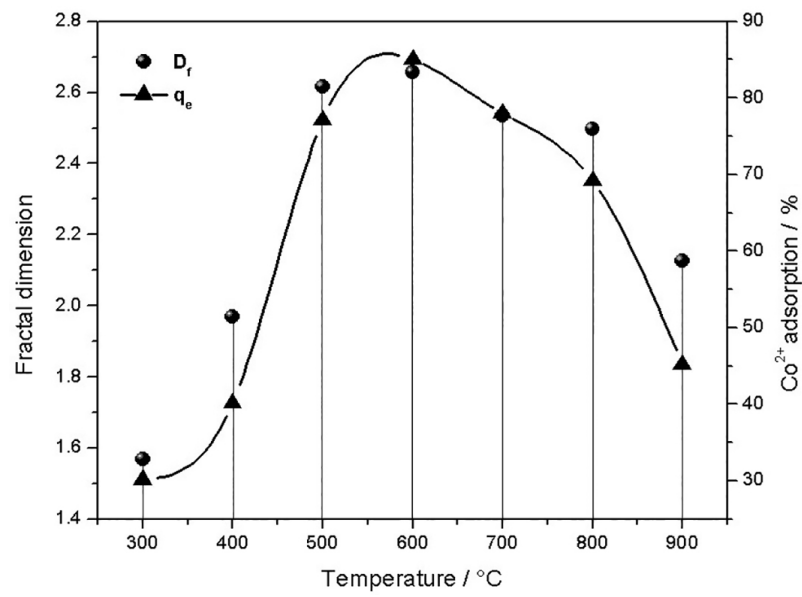

Figure 5. Surface fractal dimensions $\left(D_{f}\right)$ of rice hull ash samples prepared by solid-combustion method at different temperatures (O), and their respective $\mathrm{Co}^{2+}$ adsorption capacities $\left(\mathrm{q}_{\mathrm{e}}\right)(\boldsymbol{\Delta})$.

occurred and no cobalt precipitation was involved. The XRD results from the COMB-600 sample indicate that this sample developed an amorphous phase that facilitates cobalt adsorption. In this sense, potential adsorbents for adsorption purposes can be crystalline or amorphous. The crystalline solid adsorbents have remarkable narrow pore size distributions, due to their well-defined atomic positions, whereas amorphous solid adsorbents have broader pore size distribution, due to the more random distribution of bond angles and bond lengths among their atoms. ${ }^{32}$ Recent work ${ }^{33}$ has demonstrated that amorphous/ disordered materials may form percolation pathways via the opening of active diffusion channels, which could not only potentially facilitate ions adsorption, but also enhance mass transport within these phases. In addition, defects induced by amorphous phases lead to unexpected active sites that enhance the adsorption capability. ${ }^{34}$ The high specific surface area of the material had a considerable influence on its cobalt retention efficiency: fractal dimension analysis indicated that the material has highly rough surfaces $\left(D_{f}=2.56\right)$. Furthermore, a correlation was found between fractal dimension values and $\mathrm{Co}^{2+}$ ion adsorption capacity (Figure 5). In samples thermally treated between 700 and $1000{ }^{\circ} \mathrm{C}$, the $\mathrm{Co}^{2+}$ adsorption behavior was reduced as temperature was increased in concordance with crystalline silica formation. In a sample heated to $1000{ }^{\circ} \mathrm{C}$, the $\mathrm{Co}^{2+}$ adsorption capacity was only $6.08 \%$ (Figure 6).

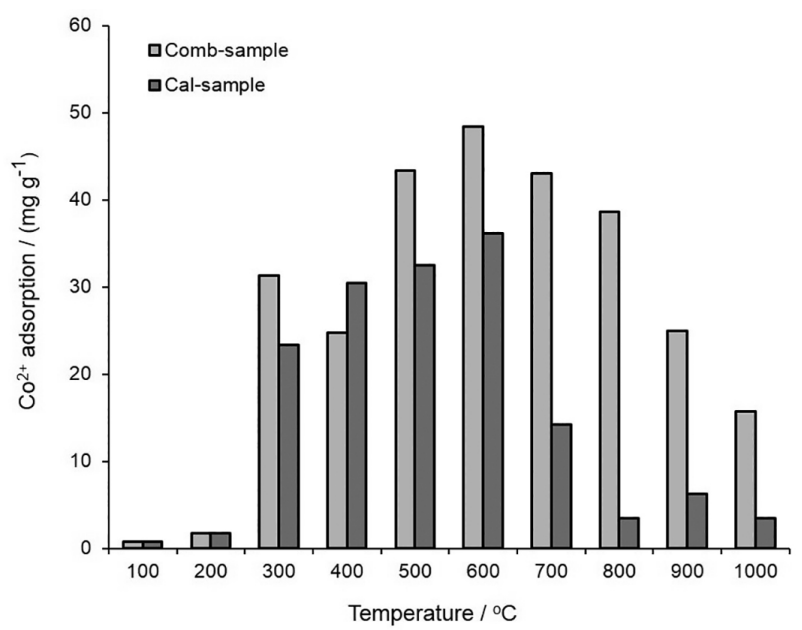

Figure 6. $\mathrm{Co}^{2+}$ adsorption on rice-hull ash samples prepared via solidcombustion and solid-calcination and thermally treated at various temperatures.

The BET specific surface area of the calcined RHA sample (CAL-300) was only $160.84 \mathrm{~m}^{2} \mathrm{~g}^{-1}$. The best $\mathrm{Co}^{2+}$ adsorption capacity observed was $48.35 \mathrm{mg} \mathrm{g}^{-1}$; this capacity was obtained with the chemical combustion sample with the highest BET surface area. The evolution of structural and textural forms therefore appears to be highly relevant, and the amount of cobalt retained on the RHA powder samples appears to be dependent on the preparation method. 
This study of calcined and combustion RHA samples has shown that the combustion process significantly impacts the surface reactivity of RHA and thereby affects its adsorption properties.

Finally, a comparison of cobalt adsorption $\left(\mathrm{q}_{\mathrm{ad}}\right)$ by other reported adsorbents (Table 3), ensures the potential application of RHA adsorbent for cobalt wastewater treatment processes.

Table 3. $\mathrm{Co}^{2+}$ adsorption capacities $\left(\mathrm{q}_{\mathrm{ad}}\right)$ of reported adsorbents

\begin{tabular}{lcc}
\hline Adsorbent & $\mathrm{q}_{\text {ads }} /\left(\mathrm{mg} \mathrm{g}^{-1}\right)$ & Reference \\
\hline Lemon peel waste & 22.00 & 35 \\
Almond green hull & 45.50 & 36 \\
Activated carbon from hazelnut shells & 13.88 & 37 \\
Al-pillared bentonite clay & 38.61 & 38 \\
Carbonous material from exhausted coffee & 24.69 & 39 \\
Fe-Mn binary oxide & 32.25 & 40 \\
Rice hull ash & 48.35 & present work \\
\hline
\end{tabular}

\section{Conclusions}

This study shows that combustion can produce materials with porous morphologies in only $5 \mathrm{~min}$. We conclude that we have successfully prepared RHA with increased porosity using an easy and fast solid-combustion process in a single step at relatively low thermal temperatures $\left(400-700^{\circ} \mathrm{C}\right)$. These results suggest that even fuel-lean combustion procedures can lead to appropriate RHA phase formation when urea is used as the fuel. The highest amount of $\mathrm{Co}^{2+}$ retained in samples modified by the solid-combustion process was $48.35 \mathrm{mg} \mathrm{g}^{-1}$, while the highest amount of $\mathrm{Co}^{2+}$ ions retained in samples modified by the solid-calcination process was $36.18 \mathrm{mg} \mathrm{g}^{-1}$. The materials modified by the solid-combustion process therefore performed better than the materials modified by the solid-calcination process. These results demonstrate the importance of preparation method, as the choice of method affects the textural characteristics and the adsorption properties of the materials: the high cobalt adsorption of the studied materials was related to the surface properties of the materials. Our research also shows that it is possible to obtain modified RHA samples with high specific surface areas (up to $243.03 \mathrm{~m}^{2} \mathrm{~g}^{-1}$ ) and homogeneous microstructures (pore size and crystalline structure) in only 5 minutes via a solid-combustion process. Experimental fractal analysis has shown that the degree of surface irregularities can be expressed by the parameter $D_{\mathrm{f}}$. Together with the textural properties of the samples, $D_{f}$ can be used to describe the surface properties of the RHA: fractal dimensions and BET surface areas are well correlated with $\mathrm{Co}^{2+}$ ion adsorption in combustion RHA samples. The experimental results revealed that modified RHA is an efficient material for quantitative cobalt ion adsorption from aqueous solutions.

\section{Acknowledgments}

The authors gratefully acknowledge the financial support of ININ, Project No. CB-207 (stages I, II and III) and the support of UNAM. We also thank Mr. MuñozLujano Jesús for technical help.

\section{References}

1. Srivastava, V. C.; Mall, I. D.; Mishra, I. M.; J. Hazard. Mater. 2006, 134, 257.

2. An, D.; Gou, Y.; Zhu, Y.; Wang, X.; Chem. Eng. J. 2010, 162, 509.

3. Danish, M.; Hashim, R.; Ibrahim, M. N. M.; Sulaiman, O.; Wood Sci. Tech. 2014, 48, 1069.

4. Gregg, S. J.; Sing, K. S. W.; Adsorption, Surface Area and Porosity; Academic Press: Exeter, U. K., 1992.

5. Ordoñez-Regil, E.; Granados-Correa, F.; Ordoñez-Regil, En.; Almazán-Torres, M. G.; Environ. Technol. 2015, 36, 188.

6. Chandradas, J.; Kim, K. H.; Adv. Powder Technol. 2010, 21, 100.

7. Patil, K. C.; Aruna, S. T.; Mimami, T.; Solid State Mater. 2002, 6, 507.

8. Chandrappa, K. G.; Venkatesha, T. V.; Nayana, K. O.; Punithkumar, M. K.; Mater. Corros. 2011, 62, 1.

9. Lagashetty, A.; Vijayanand, H.; Basavaraja, S.; Mallikarjuna, N. N.; A. Venkataraman, A.; Bull. Mater. Sci. 2010, 33, 1.

10. Maliyekkal, S. M.; Anshup; Antony, K. R.; Pradeep, T.; Sci. Total Environ. 2010, 408, 2273.

11. Sari, A.; Tuzen, M.; Citak, D.; Soylak, M.; J. Hazard. Mater. 2007, 148, 387.

12. Slejko, F. L.; Adsorption Technology: A Step-by-Step Approach to Process Evaluation and Application; Marcel Dekker Inc.: New York, 1985.

13. Bai, J.; Du, Q.; Li, G.; Li, C. Y.; Zhao, Y.; Liu, J.; Ceram.-Silik. 2012, 56, 20.

14. Ismail, M. K. I.; Pfeifer, P.; Langmuir 1994, 10, 1532.

15. Vilchis-Granados, J.; Granados-Correa, F.; Barrera-Díaz, C. E.; Appl. Surf. Sci. 2013, 279, 97.

16. Aparicio, P.; Pérez-Berbal, J. L.; Galán, E.; Bello, M. A.; Clay Miner. 2004, 39, 75.

17. Dobrescu, G.; Berger, D.; Papa, F.; Ionescu, N. I.; Rusu, M.; J. Optoelectron. Adv. Mater. 2003, 5, 1433.

18. Granados-Correa, F.; Bonifacio-Martínez, J.; Lara, V. H.; Bosch, P.; Bulbulian, S.; Appl. Surf. Sci. 2008, 254, 4688.

19. Quing-Feng, H.; Xian-Cai, L.; Xian-Dong, L.; Bai-Xing, H.; Ju-Qing, C.; Jian, S.; Surf. Coat. Technol. 2005, 190, 394. 
20. Raoufi, D.; Kiasatpour, A.; Fallah, H. R.; Rozatian, A. S. H.; Appl. Surf. Sci. 2007, 253, 9085.

21. Gupta, N.; Kushwaha, A. K.; Chattopadhyaya, M. C.; Adv. Mater. Lett. 2011, 2, 309.

22. Caramalặu, C.; Bulgariu, L.; Macoveanu, M.; Chem. Bull. “Politeh.” Univ. Timisoara 2009, 54, 13.

23. Rengaraj, S.; Moon, S.; Water Res. 2002, 36, 1783.

24. Abbas, M.; Kaddour, S.; Trari, M.; J. Ind. Eng. Chem. 2014, 20, 745 .

25. Payne, L. R.; Occup. Med. 1977, 27, 20.

26. Barceloux, D. G.; Barceloux, D.; Clin. Toxicol. 2010, 37, 201.

27. Pfeifer, P.; Cole, M.; J. Phys. 1990, 14, 221.

28. Granados-Correa, F.; Jiménez-Becerril, J.; J. Ceram. Process. Res. 2012, 13, 142.

29. Telep, G.; Boltz, D. F.; Anal. Chem. 1952, 24, 945.

30. Sing, K. S. W.; J. Porous Mater. 1995, $2,5$.

31. Benes, P.; Majer, V.; Trace Chemistry of Aqueous Solution; Elsevier: Amsterdam, 1980.

32. Granados-Correa, F.; Bonifacio-Martínez, J.; HernándezMendoza, H.; Bulbulian, S.; Water, Air, Soil Pollut. 2015, 226, 281.
33. Lee, J.; Urban, A.; Li, X.; Su, D.; Hautier, G.; Ceder, G.; Science 2014, 343, 59.

34. Uchaker, E.; Zheng, Y. Z.; Li, S.; Candelaria, S. L.; Hu, S.; Cao, G. Z.; J. Mater. Chem. A 2014, 2, 18208.

35. Bhatnagar, A.; Minocha, A. K.; Sillanpää, M.; Biochem. Eng. J. 2010, 48, 181.

36. Ahmadpour, A.; Tahmasbi, M.; Bastami, T. R.; Besharati, J. A.; J. Hazard. Mater. 2009, 166, 925.

37. Demirbaş, E.; Adsorpt. Sci. Technol. 2003, 21, 951.

38. Manohar, D. M.; Noeline, B. F.; Anirudhan, T. S.; Appl. Clay Sci. 2006, 31, 194.

39. Serrano-Gómez, J.; López-González, H.; Olguín, M. T.; Bulbulian, S.; J. Environ. Manage. 2015, 156, 121.

40. Granados-Correa, F.; Bulbulian, S.; Water, Air, Soil Pollut. 2012, $223,4089$.

Submitted: April 19, 2016

Published online: July 18, 2016 